\title{
Dangers of Oxytocin-induced Labour to Fetuses
}

\author{
W. A. LISTON, A. J. CAMPBELL
}

British Medical fournal, 1974, 3, 606-607

\section{Summary}

A retrospective survey of 658 consecutive deliveries in Aberdeen Maternity Hospital in 1970 showed that fetal distress, low Apgar score at five minutes, and special nursery admission were all common in patients receiving oxytocin infusion. Many patients receiving such infusions also had very frequent contractions when compared with others. Though the populations in each group were not standard, the clinical criteria were crude, and the survey was retrospective there are resonable grounds to believe that the present enthusiasm for oxytocin has perhaps led us in clinical practice to underestimate and forget the dangers of oxytocin to the fetus. Careful monitoring of the fetus of the mother receiving oxytocin is essential.

\section{Introduction}

The use of oxytocin is now widespread in obstetrics, and it is particularly useful for induction of labour and shortening the induction-delivery interval (Bradford and Gordon, 1968; Turnbull and Anderson, 1968). Great enthusiasm has developed recently for so-called "accelenated labour" (O'Driscoll et al., 1969; Tacchi, 1971), but oxytocin has its dangers and in the present enthusiasm these tend to be forgotten (Baird, 1971). Kubli and Rüttgers (1971) point out the hazard to the fetus succinctly in a chapter called "Iatrogenic Fetal Hypoxia." In an effort to identify and emphasize the problem our retrospective study was conceived.

\section{Methods}

The case notes of 658 consecutive deliveries in 1970 in Aberdeen Maternity Hospital were studied. Twin deliveries were excluded. Besides the normal data of age, parity, and gestation the following features were particularly noted: (a) the presence or absence of fetal distress. Fetal distress was signified by meconium staining of the liquor or a sustained fetal heart rate of above 160 beats/min or below 120 beats/min; (b) whether oxytocin stimulation was used or not and the dosage used. Doses of $32 \mathrm{mU} / \mathrm{min}$ or less were arbitrarily labelled low doses and those of more than $32 \mathrm{mU} / \mathrm{min}$ were labelled high doses; (c) whether induction of labour by amniotomy was performed or not; $(d)$ the neonatal Apgar score at one and five minutes; (e) whether the baby required special nursery admission or not; $(f)$ whether the uterine contractions occurred more often than every two minutes or not. Such patients were deemed to have "frequent contractions."

The data for each patient were collected from case notes on a specially designed punch document and subsequently transferred to magnetic tape for analysis by the I.C.L. 4120

\footnotetext{
Department of Obstetrics and Gynaecology, University of Aberdeen, Aberdeen AB9 2ZD

W. A. LISTON, M.R.C.o.G., Lecturer

School of Mathematics, Robert Gordon's Institute of Technology, Aberdeen

A. J. CAMPBELL, M.sc., Lecturer
}

computer at Robert Gordon's Institute of Technology. Analysis mainly consisted of cross classifying the patients into groups according to such criteria as level of oxytocin employed, whether fetal death occurred, etc. Where it was necessary to compare the proportions of patients in two groups a z-test was used (the $P$ values quoted refer to this test). The number of patients involved did not allow meaningful comparison of perinatal mortality to be made.

\section{Results}

The cases were divided into four categories: 325 patients $(49.4 \%)$ had normal spontaneous labour without oxytocin, $148(22.5 \%)$ had amniotomy alone to induce labour, 143 $(21.7 \%)$ had oxytocin in low dosage to stimulate labour with or without amniotomy, and $42(6.4 \%)$ had oxytocin in high dosage to stimulate labour with or without amniotomy. Onequarter of the patients thus received oxytocin.

The incidence of fetal distress for patients in the four categories is shown in table I. The significances of the differences between the groups are shown in table II. There was no significant difference between low- and high-dose cases $(z=$ $1 \cdot 142, P>0.05)$. Thus, fetal distress was significantly commoner in patients receiving oxytocin than in the others. A similar comparison for the incidence of low Apgar scores is shown in tables III and IV, such scores being more common in oxytocin patients There was again no significant difference between the oxytocin categories $(z=1.07, P>0.05)$.

\begin{tabular}{|c|c|c|c|}
\hline & & \multicolumn{2}{|c|}{ Proportion of Cases } \\
\hline & & No. & $\%$ \\
\hline $\begin{array}{l}\text { No amniotomy } \\
\text { Amniotomy and no oxytocin } \\
\text { Low-dose oxytocin .. } \\
\text { High-dose oxytocin .. }\end{array}$ & $\begin{array}{ll}\cdots & \cdots \\
\cdots & \cdots \\
\cdots & \cdots\end{array}$ & $\begin{array}{l}44 \\
17 \\
32 \\
13\end{array}$ & $\begin{array}{l}13 \cdot 5 \\
11 \cdot 5 \\
22 \cdot 4 \\
31 \cdot 0\end{array}$ \\
\hline
\end{tabular}

TABLE II-Statistical Comparisons of Incidence of Fetal Distress in the Four Groups

\begin{tabular}{|c|c|c|c|c|}
\hline & & & No Amniotomy & Amniotomy Only \\
\hline Low-dose oxytocin . . & . & $\ldots$ & $\begin{array}{c}z=2.41 \\
p<0.05\end{array}$ & $\begin{array}{l}z=2.48 \\
p<0.005\end{array}$ \\
\hline High-dose oxytocin .. & . & $\cdots\{$ & $\begin{array}{l}\mathrm{z}=2.95 \\
\mathrm{p}<0.01\end{array}$ & $\begin{array}{l}\mathrm{z}=3.06 \\
\mathrm{p}<0.01\end{array}$ \\
\hline
\end{tabular}

TABLE III-Incidence of Apgar Score $<8$ at 5 Minutes in each Labour Group

\begin{tabular}{|c|c|c|c|}
\hline & & \multicolumn{2}{|c|}{ Proportion of Cases } \\
\hline & & No. & $\%$ \\
\hline $\begin{array}{l}\text { No amniotomy } \\
\text { Amniotomy and no oxytocin } \\
\text { Low-dose oxytocin .. } \\
\text { High-dose oxytocin.. }\end{array}$ & $\begin{array}{ll}\cdots & \cdots \\
\cdots & \cdots \\
\cdots & \cdots\end{array}$ & $\begin{array}{r}19 \\
6 \\
18 \\
8\end{array}$ & $\begin{array}{r}5 \cdot 8 \\
4 \cdot 1 \\
12 \cdot 6 \\
19 \cdot 0\end{array}$ \\
\hline
\end{tabular}

TABLE IV-Statistical Comparisons of Incidence of Low Apgar Scores in the Four Groups

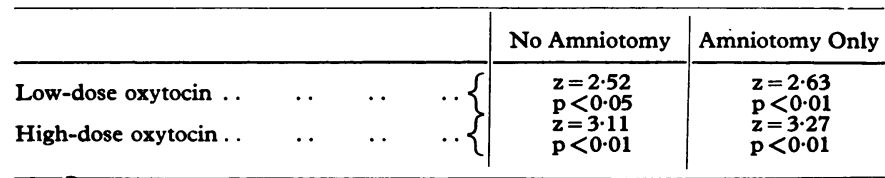


The incidence of special nursery admission is shown in table V, and the statistical comparison is shown in table VI.

TABLE v-Incidence of Admissions to Special Nursery in each Labour Group

\begin{tabular}{|c|c|c|c|}
\hline & & \multicolumn{2}{|c|}{ Proportion of Cases } \\
\hline & & No. & $\%$ \\
\hline $\begin{array}{l}\text { No amniotomy } \\
\text { Amniotomy and no oxytocin } \\
\text { Low-dose oxy tocin .. } \\
\text { High-dose oxytocin .. }\end{array}$ & $\begin{array}{ll}\cdots & \cdots \\
\cdots & \cdots \\
\cdots & \cdots\end{array}$ & $\begin{array}{l}12 \\
13 \\
18 \\
10\end{array}$ & $\begin{array}{r}3 \cdot 7 \\
8 \cdot 8 \\
12 \cdot 6 \\
23 \cdot 8\end{array}$ \\
\hline
\end{tabular}

TABLE VI-Statistical Comparisons of Incidence of Special Nursery Admission in the Four Groups

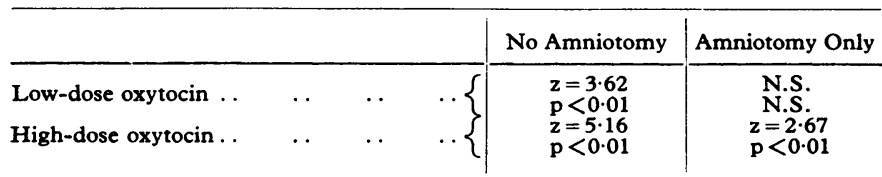

There was a slight departure from the pattern established for the other two values. While there was a significantly lower proportion of admission for the no-amniotomy cases comrpared with the low- and high-dose oxytocin cases the difference for amniotomy alone and low-dose oxytocin was not significant at the $P=0.05$ level $(z=1.05)$. The difference for the two oxytocin categories was, as before, not significant $(\mathrm{z}=1.78, \mathrm{P}>0.05)$. This value, unlike the others, is more liable to be influenced by factors originating in the infant rather than in the mother so that some minor departure from the earlier patterns would not be unexpected. Since almost all preterm infants are automatically admitted to the special nursery we decided to consider only babies of over 38 weeks gestation thereby avoiding a possible distortion of the pattern. In summary, it seems from table $\mathrm{V}$ that special nursery admission is commoner in cases where oxytocin is used.

In patients receiving oxytocin, especially in high doses, contraction rates exceeding one every two minutes were significantly commoner (table VII). The significances of these

TABLE VII-Incidence of Frequent Contractions in each Labour Group

\begin{tabular}{|c|c|c|c|c|}
\hline & & & \multicolumn{2}{|c|}{ Proportion of Cases } \\
\hline & & & No. & $\%$ \\
\hline $\begin{array}{l}\text { No amniotomy } \\
\text { Amniotomy and no oxytocin } \\
\text { Low-dose oxytocin .. } \\
\text { High-dose oxytocin .. }\end{array}$ & $\begin{array}{l}\ldots \\
\cdots \\
\ldots\end{array}$ & $\begin{array}{l}\ldots \\
\ldots \\
\ldots\end{array}$ & $\begin{array}{l}21 \\
12 \\
41 \\
21\end{array}$ & $\begin{array}{r}6 \cdot 5 \\
8 \cdot 1 \\
28 \cdot 7 \\
50 \cdot 0\end{array}$ \\
\hline
\end{tabular}

TABLE VIII-Statistical Comparisons of Incidence of Frequent Contractions in the Four Groups

\begin{tabular}{llll|c|c}
\hline Low-dose oxytocin.. & $\ldots$ & $\ldots$ & $\ldots\{$ & No Amniotomy & Amniotomy Only \\
\hline High-dose oxytocin .. & $\ldots$ & $\ldots$ & $\ldots\left\{\begin{array}{l}\mathrm{z}=6.05 \\
\mathrm{p}<0.01 \\
\mathrm{z}=8.32 \\
\mathrm{p}<0.01\end{array}\right.$ & $\begin{array}{l}\mathrm{z}=4.5 \\
\mathrm{p}<0.01 \\
\mathrm{z}=6.33 \\
\mathrm{p}<0.01\end{array}$ \\
\hline
\end{tabular}

TABLE IX-Relation between Frequency of Contractions and Incidence of Fetal Distress, Low Apgar Scores, and Special Nursery Admissions

\begin{tabular}{|c|c|c|c|c|c|c|}
\hline & \multicolumn{2}{|c|}{$\begin{array}{l}\text { Cases in which } \\
\text { Contractions } \\
\text { were Frequent } \\
(n=95)\end{array}$} & \multicolumn{2}{|c|}{\begin{tabular}{|c|} 
Cases in which \\
Contractions \\
were not Frequent \\
$(n=563)$
\end{tabular}} & \multirow[b]{2}{*}{$\mathbf{z}$} & \multirow[b]{2}{*}{$\mathbf{P}$} \\
\hline & No. & $\%$ & No. & $\%$ & & \\
\hline Fetal distress $\quad \ldots$ & 28 & $29 \cdot 5$ & 77 & $13 \cdot 7$ & 3.89 & 0.01 \\
\hline $\begin{array}{l}\text { (after } 38 \text { weeks) } \\
\text { Apgar scores }<8 \ldots\end{array}$ & $\begin{array}{l}17 \\
16\end{array}$ & $\begin{array}{l}17.9 \\
16.8\end{array}$ & $\begin{array}{l}35 \\
35\end{array}$ & $\begin{array}{l}6.2 \\
6.2\end{array}$ & $\begin{array}{l}3.91 \\
3.58\end{array}$ & $\begin{array}{l}0.01 \\
0.01\end{array}$ \\
\hline
\end{tabular}

differences are shown in table VIII. This time the difference between low-dose and high-dose oxytocin was significant (z $=2.75, \mathrm{P}<0.05$ ). Not surprisingly the incidences of fetal distress, low Apgar scores, and special nursery admission were significantly greater among cases with frequent contractions than in others (table IX).

\section{Discussion}

It may be self-evident that frequent contractions of the uterus in response to oxytocin stimulation can interfere with the uterine blood flow and so produce distress in the fetus, but clearly in our own hospital practice this fact is not widely appreciated, and we suspect that in the present climate of enthusiasm for oxytocin it is a fact which is readily forgotten.

Turnbull and Anderson (1968) noted an increased incidence of fetal distress after the introduction of their new accelerated labour regimen in Aberdeen. They also noted three stillbirths which they attributed to oxytocin being used to overcome pelvic contraction. Beazley and Kurjak (1972) also noticed an increased incidence of fetal distress in patients -especially multiparous ones whose labour was stimulated with oxytocin.

The criteria which we used in this survey were necessarily crude-clinical fetal distress and the frequency of contractions-and as the survey was retrospective they may have been inaccurate. It can be argued also that the type of patient in each category is necessarily different-that is, patients in spontaneous labour are different from those requiring amniotomy to induce labour and these are different again from those requiring amniotomy and oxytocin. Those with oxytocin clearly have a higher risk of fetal distress than those with none, however, and this is especially so in those receiving the higher doses.

Likewise our measurements of neonatal welfare-fiveminute Apgar scores under eight and special nursery admission-were crude, as many other factors influence these values. Nevertheless, babies from patients receiving oxytocin, especially in high doses, were statistically more likely to have such low Apgar scores and to need nursery admission.

Contractions occurring more often than every two minutes are clearly more likely to cause fetal distress, to depress a baby's Apgar score, and to make it more liable for special nursery admission. Such contractions are more likely to be caused by high-dose oxytocin.

Oxytocin is a potent and useful drug of enormous benefit to women in labour. It is important to remember that like all potent drugs it also has potential for harm and that it must be used carefully. We do not want to put the clock back, but it must be remembered that a speedy and convenient labour though often desirable is not the most important goal of the obstetrician. Careful monitoring of the fetus when the mother is receiving oxytocin is essential, and high doses of oxytocin must be given with special care. With high doses of oxytocin we suggest that the fetus should be monitored with modern equipment allowing continuous observation of the fetal heart rate, by $\mathrm{pH}$ sampling of the fetal scalp and by careful recording of uterine contractions.

\section{References}

Baird, D. T. (1971). Personal communication.

Beazley, J M and Kuriak, A. (1972), Lancet, 348.

Bradford, W. P., and Gordon, G. (1968). Fournal of Obstetrics and Gynaecology of the British Commonwealth, 75, 698 .

Kubli, F., and Rüttgers, W. (1971). In Physiology and Pathology in the Perinatal Period, ed. R. H. Gevers and J. H. Ruys, p. 57. Leiden, Leiden University Press.

O'Driscoll, K., Jackson, R. J. A., and Gallagher, J. T. (1969). British Medical fournal, 2, 477.

Tacchi, D. (1971). Lancet, 2, 1134.

Turnbull A C., and Anderson A. B. M. (1968). Fournal of Obstetrics and Gynaecology of the British Commonwealth, 75, 32. 